\title{
Internato Rural em Saúde Coletiva com ênfase em Saúde da Família e Programa Mais Médicos: Uma proposta de integração para a formação médica.
}

\section{Internship in Rural Collective Health with emphasis on Health and Family Program More Care: An integration proposal for medical education.}

\section{Internado en Salud Colectiva Rural con enfasis en la Salud y el Programa de Familia Más Cuidado: Una propuesta de integración de educación médica.}

Valdir Francisco ODORIZZI ${ }^{1}$

Rogério Ferreira MARQUEZAN ${ }^{2}$ Ana Letícia Covre ODORIZZI ${ }^{3}$

Kezia Cristina Araujo de NOÁ 4

Analice Oliveira da CRUZ ${ }^{5}$

RESUMO: O presente trabalho apresenta uma proposta que visa promover a formação ética, técnica e política dos acadêmico-multiplicadores participantes, fato de fundamental importância no processo de educação em saúde, instrumentalizando a problemática e o mecanismo reflexão sobre a realidade de trabalho médico no interior do país. Essa proposta ainda acrescenta a concepção de um processo de formação acadêmica ao mesmo tempo inovadora e inclusiva, que permitirá a visualização dos programas políticos em curso, e também a auto-identificação e o reconhecimento 1 Possui graduação em Medicina pela Fundação Técnico Educacional Souza Marques (1983), mestrado em Ciências da Saúde pela Faculdade de Medicina de São José do Rio Preto (2003) e doutorado em Ciências da Saúde pela Faculdade de Medicina de São José do Rio Preto (2006). Atualmente é professor Adjunto III da Fundação Universidade Federal do Tocantins (UFT) no curso de Medicina, do Programa de Residência Médica da UFT nas áreas de cirurgia geral, ginecologia e medicina de família e comunidade e Coordenador da disciplina da Saúde da Mulher I (UFT), coordenador do internato de cirurgia geral do ITPAC- Porto Nacional. Tem experiência na área de Medicina, com ênfase em Ginecologia, Cirurgia Geral, Medicina de Família e Comunidade, Gerontologia. Supervisor do Programa de Valorização da atenção Básica (PROVAB) e Tutor do Programa Mais Médicos Para o Brasil, no Estado do Tocantins. Linha de pesquisa: Bioquímica Oxidativa, Saúde Pública e Medicina de família e Comunidade. Sistematização das Políticas em Saúde. 2 Psicólogo, mestre em Psicologia-Pontífica, universidade Católica de Goiás (2002). Atualmente é professor Adjunto no Centro Universitário (UNIRG) e professor do Magistério Superior da fundação Universidade Federal do Tocantins. Tem experiência na área de Psicologia Cognitiva e Apoiador Estadual do MEC para o Programa Mais Médicos para o Brasil, no Tocantins.

3 Possui graduação em Psicologia pela Fundação UNIRG (2010) Pós Graduação em Gerontologia (UFT) e Mestranda em Educação pelo PPGE UFT. Atualmente é psicóloga do Hospital Infantil de Palmas. Tem experiência na área de Psicologia e dança Clássica e Contemporânea. Também tem Formação em Ballet.

4 Estudante no curso de Comunicação Social na Fundação Universidade Federal do Tocantins (UFT).

5 Estudante no curso de Ciências Econômicas na Fundação Universidade Federal do Tocantins (UFT). 
dos acadêmicos de medicina, como protagonistas do processo, desafiando as abordagens tradicionalmente utilizadas nos cursos de Medicina e da Sistematização das Políticas de Saúde; justificando-se plenamente.

Palavras Chaves: Educação em Saúde; Formação Acadêmica; Programas Políticos em curso;

ABSTRACT: This paper presents a proposal to promote ethical, technical and policy-academic multipliers participants, a fact of fundamental importance in the health education process, providing tools for the problems and the reflection mechanism on the reality of medical work in the countryside. This proposal adds to design a process of academic training at the same innovative and inclusive time, allowing the visualization of political programs in progress, and also the selfidentification and recognition of medical students, as process protagonists, challenging approaches traditionally used in medical courses and systematization of the Health Policy; justifying fully. Keywords: Health Education; Academic education; Political ongoing programs; Systematization of Health Policies.

RESUMEN: Este artículo presenta una propuesta para promover éticas, técnicas y de política académica multiplicadores participantes, un hecho de importancia fundamental en el proceso de educación para la salud, las herramientas que proporcionan a los problemas y el mecanismo de reflexión sobre la realidad del trabajo médico en el campo. Esta propuesta se suma a diseñar un proceso de formación académica a la vez innovadora e inclusiva, permitiendo la visualización de los programas políticos en curso, así como la auto-identificación y reconocimiento de los estudiantes de medicina, como protagonistas del proceso, desafiando enfoques tradicionalmente utilizados en cursos de medicina y sistematización de la Política de Salud; justificando plenamente. Palabras clave: Educación para la Salud; Formación académica; Programas en curso Políticos; Sistematización de las Políticas sobre la Salud.

\section{INTRODUÇÃO}

Ao se refletir sobre os problemas que ocorrem no país, relacionados à carência de profissionais médicos no interior visualiza-se a possibilidade de utilizar as Escolas de Medicina para buscar formas alternativas de enfrentar esse problema e produzir estratégias de melhorar a interiorização desses profissionais. As estratégias devem direcionar-se em defesa de medidas que enfrentem os problemas de distribuição e fixação de médicos, identificando as qualidades e deficiências dos projetos implantados no Brasil à luz da experiência internacional. Defender também uma formação médica generalista que consolide no curso de graduação o conhecimento em saúde da família ${ }^{1}$. 
A atuação médica vista como "sacerdócio", principalmente dos médicos brasileiros que trabalhavam no interior, já não se faz presente na atualidade. É comum ver nas pequenas e médias cidades, Unidades de Saúde e centros hospitalares que sofrem com os escassos recursos e com equipamentos sucateados, filas de pacientes desesperados e furiosos em busca de uma simples consulta, que pudesse lhe atribuir um medicamento para curar sua doença. Esse ambiente cheio de problemas, inevitavelmente recai como sendo "culpa" do médico, pois ao mesmo tempo em que falta infra-estrutura na saúde, também falta para a população o recurso humano que é o "responsável" pelas péssimas condições de trabalho das Unidades de Saúde³

O isolamento profissional é outro importante motivo da não-permanência dos médicos em cidades menores. "Especialmente no caso de locais distantes dos grandes centros urbanos, a problemática falta de acesso à atualização profissional é, de longe, um dos fatores que mais pesam na decisão do médico. Atualmente estão disponíveis algumas ferramentas de atualização à distância incentivadas pelas entidades médicas e por instituições públicas; no entanto poucas prefeituras disponibilizam acesso à internet e/ou custeio da participação do médico em eventos científicos de atualização ${ }^{1}$.

As condições de vida e de salário exercem atração sobre o mercado de trabalho dos médicos, da mesma forma que o contexto no qual se dá a prática profissional e a existência ou não de uma política de saúde local. Além das condições especificadas acima para o exercício profissional se faz necessário discutir um plano de carreira, para que o médico possa se estabelecer no município é importante que ele tenha a segurança de que, por exemplo, ao terminar o mandato do gestor que o contratou, seu emprego continue assegurado, que a localidade lhe permita constituir família com adequadas condições de educação para seus filhos e que tenha oportunidades de lazer e meios para dar sequência a seu aprimoramento profissional e pessoal ${ }^{3}$.

Diferentes governos brasileiros já criaram programas e investiram em uma solução para a falta de atendimento básico no interior do país. Criado na gestão do ex-ministro da Saúde, José Serra, o Programa de Interiorização do Trabalho em Saúde (Pits) teve um sucesso inicial por oferecer aos médicos que o primeiro ano de trabalho nas áreas equivaleria a uma especialização. Os médicos iam com uma bolsa paga pelo CNPq, mas o índice de desistência, depois de concluído o primeiro ano, foi altíssimo 5 .

Em julho de 2013, foi proposto pela presidenta Dilma Rousseff, o Programa Mais Médicos para o Brasil (PMMB). Pautado na busca em elevar a capacidade de atendimento nas regiões carentes, como os municípios do interior e periferias de grandes cidades com a contratação também de profissionais estrangeiros como ocorre em todo o mundo, tem como meta solucionar a deficiência de médicos, a irregular distribuição dos profissionais pelo território nacional e a carência no atendimento básico de saúde da população ${ }^{6}$. 
O Programa, no entanto, é mais do que isso, e não se restringe ao tratamento dos pacientes. Coloca como prioritária uma nova visão sobre a medicina - o foco na prevenção de doenças simples e facilmente evitáveis. Objetiva reduzir os custos e os gastos com tratamentos caros, uma vez que, com o médico ao lado e pronto a prevenir o agravamento dos sintomas, não há necessidade de exames sofisticados ou grandes equipamentos para garantir a cura e o bom atendimento ${ }^{6}$.

Insere-se no programa Investimentos nas Unidades de saúde, a abertura de novas "Escolas de Medicina", além de novas vagas de residência médica com a oferta de bolsas, reformular a grade curricular dos cursos de medicina, bem como o processo de avaliação dos cursos, e selecionar médicos interessados em trabalhar no atendimento à atenção básica e urgência e emergência do SUS. A responsabilidade de buscar e aperfeiçoar esse perfil do profissional é do curso de formação. As instituições de ensino e as universidades devem ajustar suas matrizes curriculares, capacitar seus docentes, aceitar as mudanças que o tempo impõe, para poder proporcionar aos acadêmicos, pelo menos, a opção de escolha ${ }^{6}$.

Para tanto, em primeiro lugar, deve-se buscar um perfil adequado para fixação do médico no interior. Patric Paul ${ }^{2}$, nos ensina, que a função do médico de saúde pública se situa no entrecruzamento entre indivíduo e coletividade, entre as leis físico-biológicas e as leis socioculturais. Esse imperativo impõe que ele aborde o conceito de saúde de maneira muito mais ampla do que a simples prática médica. Um médico de saúde pública contribui para a saúde dos doentes por meio da sua reflexão tanto sobre o meio ambiente físico quanto sobre o meio ambiente social, a fim de melhorar o sistema coletivo de saúde. É assim que a sua ação, no âmbito de suas próprias competências ou na de uma colaboração em rede, faz com que campos diferentes daqueles da atividade médica estrita intervenham: campo econômico, ecológico, social, estatístico, cultural, etc. Ele deve sem dúvida utilizar suas ferramentas médicas, como, por exemplo, a epidemiologia, mas deve integrar os custos de saúde e a antropologia da medicina. O médico de saúde pública, por sua missão e vocação, mostra-se então, necessariamente, pluri e interdisciplinar.

Alicerçados nesse raciocínio, inserir gradativamente o acadêmico de medicina em municípios menores através do Internato Rural, devidamente tutelados e preceptorados, resultará em relevante aprendizado e experiência profissional, além de proporcionar a integração com a comunidade, observação dos problemas locais, troca de informações com profissionais antigos do município, possibilidade de trabalhar conteúdos de forma participativa numa abordagem além da narrativa histórico-crítica da construção da política do sistema público municipal de saúde, que permitirá a cada acadêmico participante o reconhecimento do seu possível lugar nessa cadeia, identificando as potencialidades e os limites de sua atuação individual. Adicionalmente, assessorados por esses preceptores, através de seminários e discussões, poderão superar as concepções tradicionais de educação e constituir uma cultura crítica da interiorização da saúde, redundando em práticas inovadoras e ativas neste terreno de complexa solução, levantando questões consideradas 
fundamentais para a efetivação das mudanças necessárias à implementação do profissional de saúde, em pequenos municípios.

\section{PROPOSTA DE INTEGRAÇÃO DO INTERNATO RURAL COM O PMMPB}

Surge, a partir da reflexão feita até aqui, a proposta de Regimentar em forma de internato rural, acadêmicos de medicina no Serviço de Saúde Pública Municipal de cidades onde atuam os profissionais do Programa Mais Médicos que passariam a atuar também como preceptores, e tutorados pelas instituições de ensino e/ou Universidades.

Tal formato permitiria ao alunos em formação decodificar e analisar o trabalho do profissional médico em Unidades de Saúde de Municípios do interior do Tocantins, ressignificando a atuação na atenção primária a partir de uma práxis monitorada por profissionais que atuam de forma diferenciada na estratégia de saúde da família.

Além disso, a proposta fortalece o tripé ensino-pesquisa-extensão ao permitir que o cenário de prática seja também utilizado para Investigar o papel das Universidades do Tocantins como precursora da descentralização da educação médica através da implementação de projetos de pesquisa a partir da experiência de integração entre formação (Internato Rural) e políticas públicas que visam o fortalecimento da Atenção Básica.

Naturalmente, durante o processo seria possível ainda identificar as dificuldades encontradas pelos alunos e preceptores nos sistemas de saúde e na operacionalização do que preconiza a Política Nacional de Atenção Básica, contribuindo para propostas de melhoria e de novas maneiras de intervir, através da educação em saúde nos Municípios do Estado do Tocantins com inovações em ações e propostas aos programas, privilegiando o bem estar físico e autoestima, estudos clínicos, diagnósticos e terapêuticos, alem da prevenção das doenças.

As cidades serão escolhidas pela estrutura de saúde, com Unidades de Saúde de Estratégia de Família, podendo ainda contar com um hospital de pequeno porte. A equipe será composta pelos acadêmicos, o preceptor, componente do PMMB, com perfil para educador, por um tutor que deve ser um professor com titulação e após o primeiro grupo será escolhido entre os acadêmicos um monitor.

Durante o semestre, um numero de pré fixado de acadêmicos (para cada cidade parceira) previamente designados pelo Departamento de Graduação e Ensino em Saúde (DGES) da Secretaria do Estado da Saúde de Tocantins, irão residir nos Municípios, por um período dois meses acompanhando os serviços de Estratégia de Saúde de Família de segunda a sexta feira com carga horária de 8 horas diárias mais um plantão de 10hs (noturno ou final de semana) no hospital, perfazendo um total de $60 \mathrm{hs}$ semanais e ao término do estágio $480 \mathrm{hs}$. 
Os preceptores vinculados ao PMMPB receberiam na sua USF de atuação, até três alunos, em caso de haver centro hospitalar um outro preceptor será destinado ao hospital e receberá também até 03 (três) alunos.

Os alunos acompanharão seus preceptores em seu ritmo de trabalho normal, com ambulatório, visitas domiciliares, atendimento no hospital, discussão de casos, participação em reuniões com os outros profissionais e comunidade.

Ao tutor caberá reunião com preceptores e acadêmicos para planejamento das ações.

Como proposta, ficará sob responsabilidade das Prefeituras das cidades parceiras a estadia e alimentação dos alunos pelo período que se mantiverem nas cidades. O DGES se responsabilizara pelos preceptores, tutor, transporte dos alunos.

\section{CONSIDERAÇÕES FINAIS}

Constata-se que desde a implantação do Sistema Único de Saúde (SUS) no final da década de 80 e início da década de 90, as escolas médicas apoiadas no modelo Flexineriano não têm conseguido formar profissionais capazes de atender a proposta de uma prática clínica ampliada e integradora das dimensões biopsicossociais do adoecimento e capaz de promover o cuidado em saúde mediante o trabalho de uma equipe multidisciplinar ${ }^{7}$..

Entretanto, a formação de profissionais alia-se a outros desafios para a efetivação do SUS como o do subfinanciamento e o da interiorização dos profissionais de saúde. Ao contrário do que se poderia imaginar, tal cenário ao longo dos anos vem demonstrando ser um terreno fértil para mudanças.

Podemos citar, por exemplo, a criação Comissão Interinstitucional para Avaliação das Escolas

\section{Médicas (CINAM) em 1991.}

Destaca-se ainda o programa de incentivo às mudanças nos cursos de Medicina - o Promed. Criado em 2001, este programa visou oferecer apoio técnico e financeiro às escolas médicas dispostas a desenvolver processos de mudança que levem a uma articulação com os serviços de saúde, à adoção de metodologias ativas de ensino-aprendizagem e a uma formação crítica e humanista do profissional médico. Além do Promed, políticas mais recentes no Brasil, como, por exemplo, os Pólos de Educação Permanente em Saúde e o Aprender SUS, aproximam os ministérios da Saúde e Educação na coordenação de ações que visam encurtar distâncias entre as escolas médicas, os serviços e a comunidade ${ }^{8}$.

Um sinal dessas mudanças é apontado por Nogueira ${ }^{7}$ é a aproximação entre Ministério da Saúde e da Educação que se inicia com políticas mais como, por exemplo, os Pólos de Educação 
Permanente em Saúde e o Aprender SUS, aproximam os ministérios da Saúde e Educação na coordenação de ações que visam encurtar distâncias entre as escolas médicas, os serviços e a comunidade ${ }^{8}$.

Nesse nessa perspectiva, o PMMPB constitui uma consolidação dessa aproximação, ao prever em seu escopo a atuação das Instituições de Ensino como um importante eixo vinculado ao processo de Educação Permanente dos profissionais de saúde.

Mais recentemente, com a publicação das novas Diretrizes Curriculares para os cursos de Medicina em 2014, observa-se que o processo de reformulação da formação médica tem exigido rompimento com paradigmas hegemônicos, o que na prática se dá através de propostas inovadoras para o ensino médico.

Acreditamos que a proposta aqui apresentada pode ser um modelos de integração ensino-serviço que contribua efetivamente com o surgimento de novas soluções para velho problemas.

\section{REFERÊNCIAS BIBLIOGRÁFICAS}

1- Lima, E.K,.C. A Dura Realidade da Profissão Médica no Interior do Brasil. Em: http:// www.soartigos.com/articles/196/1/A-Dura-Realidade-da-Profissao-Medica-no-Interior-do-Brasil-/ $\underline{\text { Inva }}$

2- Paul, P. Visão Transdisciplinar na Saúde Pública Junho de 2000. Em http://cetrans.com.br/ textos/visao-transdisciplinar-na-saude-publica.pdf.

3- O interior ainda não atrai os médicos. Em: http://www.sescsp.org.br/sesc/revistas_sesc/pb/ artigo.cfm?Edicao_Id=334\&Artigo_ID=5216\&IDCategoria.

4- Flor A. Levar médicos para o interior é desafio para governo brasileiro. Em: http://www. adital.com.br/site/noticia2.asp?lang=PT\&cod=10968.

5- Maciel Filho R, Branco MAF. RUMO AO INTERIOR: MÉDICOS, SAÚDE DA FAMÍLIA E MERCADO DE TRABALHO. Editora Fiocruz; 2008. 205 pp. Disponível em: https://maismedicos.saude.gov.br/

6- Nogueira, Maria Inês. (2009). As mudanças na educação médica brasileira em perspectiva: reflexões sobre a emergência de um novo estilo de pensamento. Revista Brasileira de Educação Médica, 33(2), 262-270. Retrieved September 27, 2015, from http://www.scielo. br/scielo.php?script $=$ sci arttext\&pid=S0100-55022009000200014\&lng=en\&tlng=pt. 10.1590/ S0100-55022009000200014. 
$122 / /$

7- Lampert, JB. Avaliação do processo de mudança na formação médica. In: Marins, JJN (et al.), org. Educação médica em transformação: instrumentos para a construção de novas realidades. São Paulo: Hucitec, 2004.

Artigo apresentado em 04-08-15 Artigo aprovado em 07-10-15 Artigo publicado no sistema em 30-12-15 